\title{
Black Adrenal Adenoma: Is it Unusual?
}

VNSSVAMS D Mahalakshmi ${ }^{1}$, Nandita Chaudhary' ${ }^{2}$, Mallika Danda ${ }^{3}$, Suneel Mattoo ${ }^{4}$, Pallavi Prasad ${ }^{5}$, Sabaretnam Mayilvaganan ${ }^{6}$, Amit Agarwal $^{7}$

\section{Abstract}

A 21 years old lady presented with swelling of feet and face. Weight gain and stretch marks with cushingoid features on examination with hirsutism and she had a right adrenal adenoma measuring $3 \times 2.5 \times 1.5 \mathrm{~cm}$ which was black colored. We discuss this black colored adenoma in this image of interest.

Keywords: Adrenal adenoma, Cushing's syndrome, Thyroid surgery.

World Journal of Endocrine Surgery (2019): 10.5005/jp-journals-10002-1253

\section{CASE}

A 21-year-old lady presented with chief complaints of swelling of feet and face, weight gain, and stretch mark over abdomen since

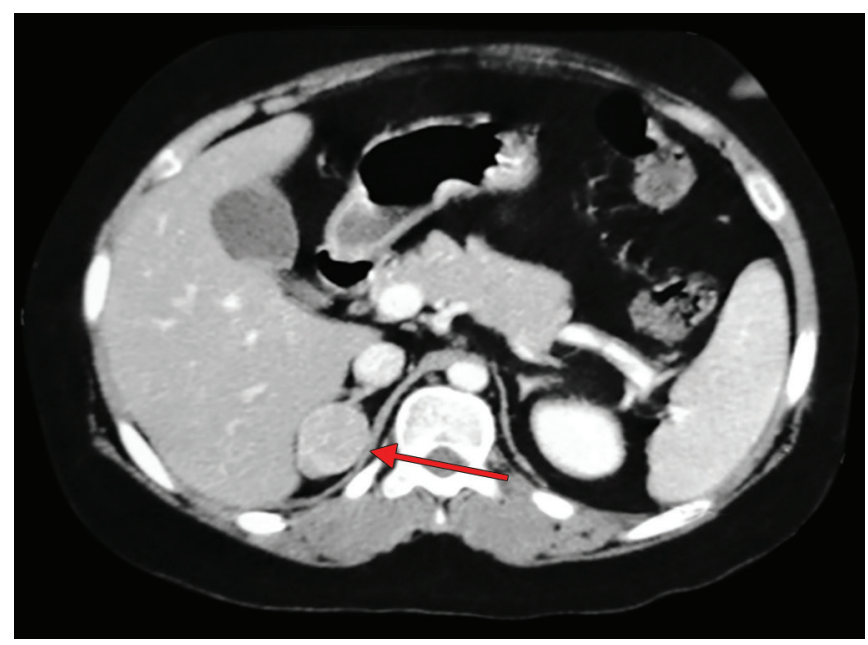

Fig. 1: Contrast-enhanced computed tomography (CECT) showing right-sided adrenal adenoma

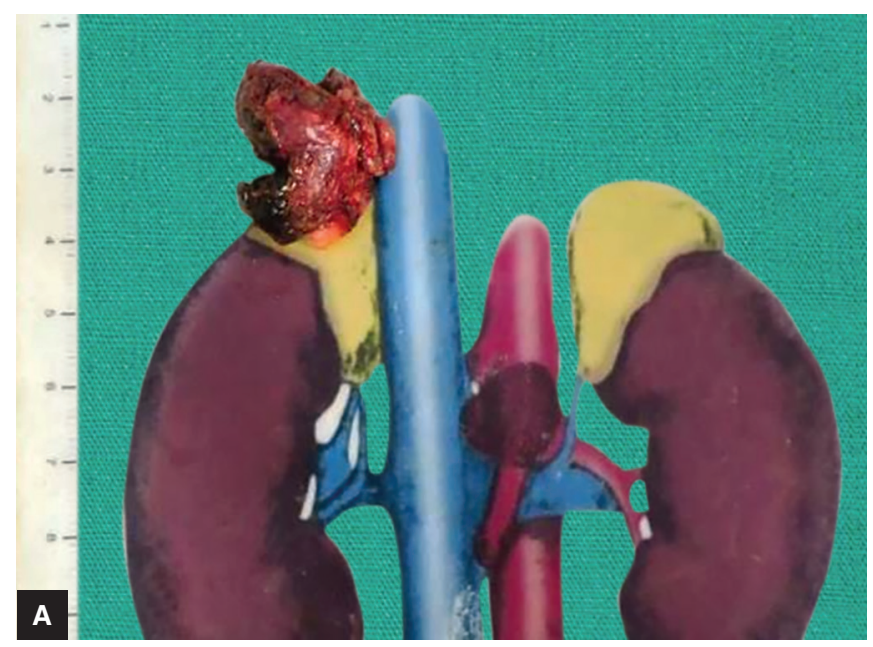

${ }^{1-7}$ Department of Endocrine and Breast Surgery, Sanjay Gandhi Postgraduate Institute of Medical Sciences, Lucknow, Uttar Pradesh, India

Corresponding Author: Amit Agarwal, Department of Endocrine and Breast Surgery, Sanjay Gandhi Postgraduate Institute of Medical Sciences, Lucknow, UttarPradesh,India,Phone:+91 8004904645 , e-mail: amit@sgpgi.ac.in

How to cite this article: Mahalakshmi VD, Chaudhary N, Danda M, Mattoo S, Prasad P, Mayilvaganan S, Agarwal A. Black Adrenal Adenoma: Is it Unusual? World J Endoc Surg 2019;11(1):33-35.

\section{Source of support: Nil}

\section{Conflict of interest: None}

4 years. She had a history of delayed and irregular menses associated with the appearance of facial hair, hair on the lower body, and loss of hair over scalp. She had not taken any exogenous steroid. She had deepening of voice which has increased significantly over the last 1 year with a history of bone pains since 1 year and a history of easy bruisability since 1 year. She had Cushingoid features with hirsutism on examination. Her laboratory workup revealed adrenocorticotropic hormone (ACTH)-independent Cushing's syndrome and imaging revealed an adrenal adenoma measuring $3 \times 2.5 \mathrm{~cm}$ on the right side. She underwent laparoscopic

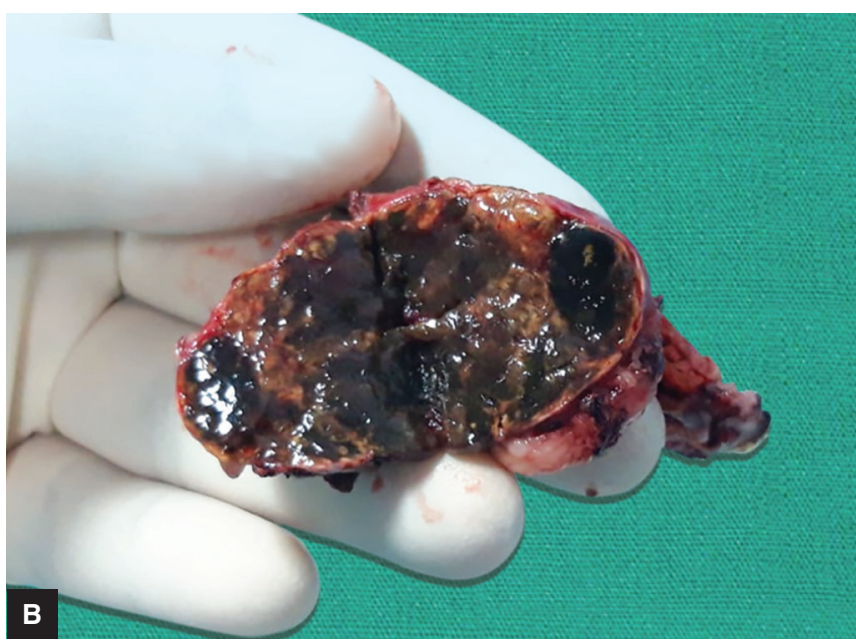

Figs 2A and B: Gross specimen after surgery and after bisection

(0) The Author(s). 2019 Open Access This article is distributed under the terms of the Creative Commons Attribution 4.0 International License (https://creativecommons. org/licenses/by-nc/4.0/), which permits unrestricted use, distribution, and non-commercial reproduction in any medium, provided you give appropriate credit to the original author(s) and the source, provide a link to the Creative Commons license, and indicate if changes were made. The Creative Commons Public Domain Dedication waiver (http://creativecommons.org/publicdomain/zero/1.0/) applies to the data made available in this article, unless otherwise stated. 


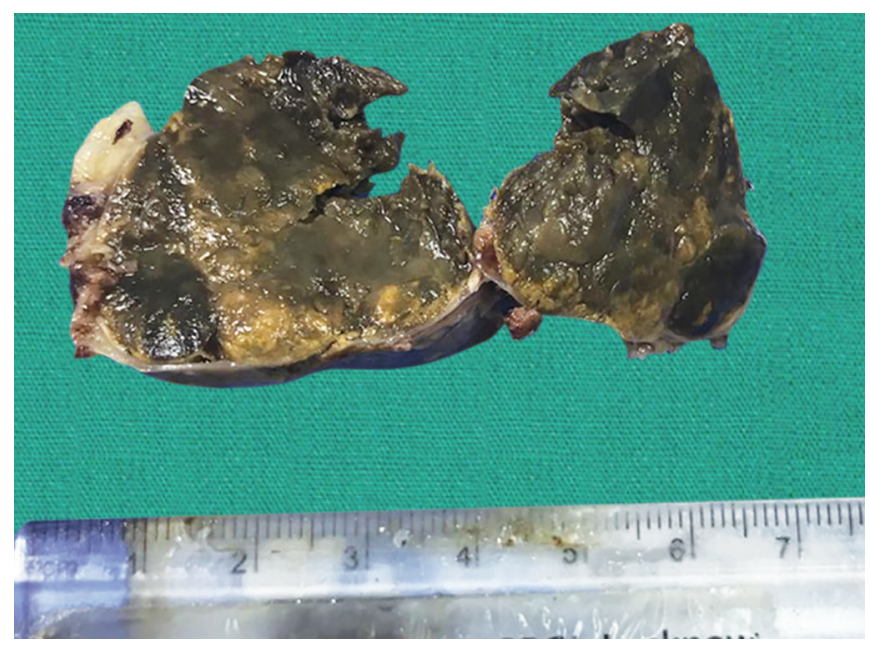

Fig. 3: Gross specimen after formalin fixation

transperitoneal right adrenalectomy. We found a black adrenal adenoma measuring $3.5 \times 2.5 \times 1.5 \mathrm{~cm}$. She has an uneventful postoperative recovery. She was discharged on postoperative day (POD) 6 with serum cortisol $<27.6 \mathrm{nmol} / \mathrm{L}$ and on wysolone $6.5 \mathrm{mg}$. Final histopathology was suggestive of pigmented adrenal cortical adenoma (Figs 1 to 4).

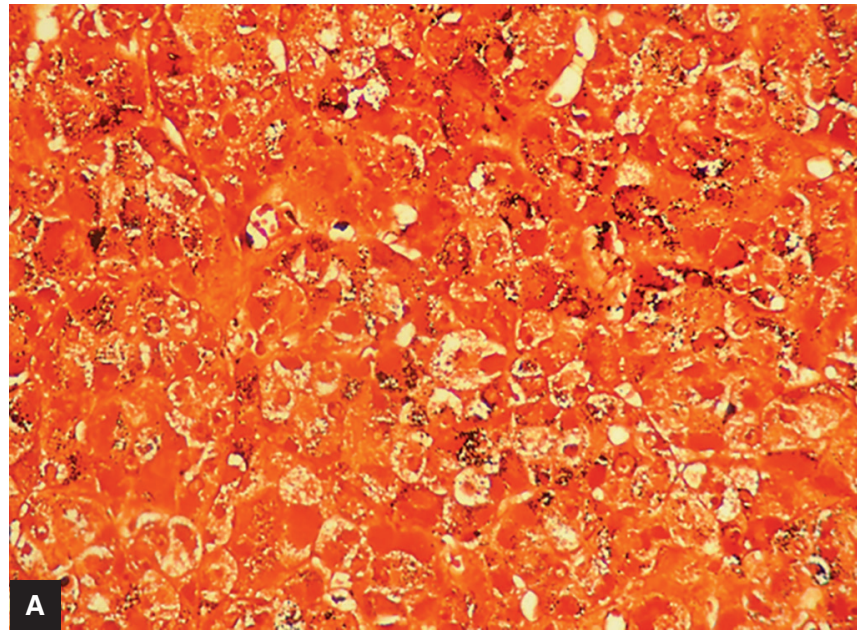

\section{Discussion}

Black adenomas ${ }^{1}$ are adenomas that have a dark brown to black color because of the presence of pigment, thought to represent either lipofuscin ${ }^{2}$ or neuromelanin. ${ }^{3}$ The former interpretation is more likely, the pathogenesis being probably related to alterations of lipid metabolism induced by the abnormal mitochondria present in the cells of these lesions. Most of these "black adenomas" or "black nodules" are nonfunctioning and found incidentally at autopsy, but on occasion, they have been associated with primary aldosteronism ${ }^{4}$ or Cushing's syndrome $\mathrm{e}^{5}$ as in this case. These nodules have a higher radiological density than the ordinary yellow cortical tumors. ${ }^{5}$ In a series ${ }^{6}$ of 115 adrenal cortical tumors from surgical adrenal samples in Cedars-Sinai Medical Center, not a single black adrenal adenoma was encountered. Although the incidence of black adrenal adenomas has not been formally addressed in other surgical series, the mostly single-case reports of this unique-colored tumor even recently suggested that they are indeed rare in surgical adrenal samples. ${ }^{7}$ The discrepancy between the high frequency of incidental black adrenal adenomas in autopsy findings and their exceptionally low incidence in surgical series may be due to the small size and nonfunctional nature of the adenomas which avoid the surgery in spite of the tumors' radiological features. Most of the black adrenal adenomas, like in this case, cause ACTH-independent Cushing's syndrome, some cause primary

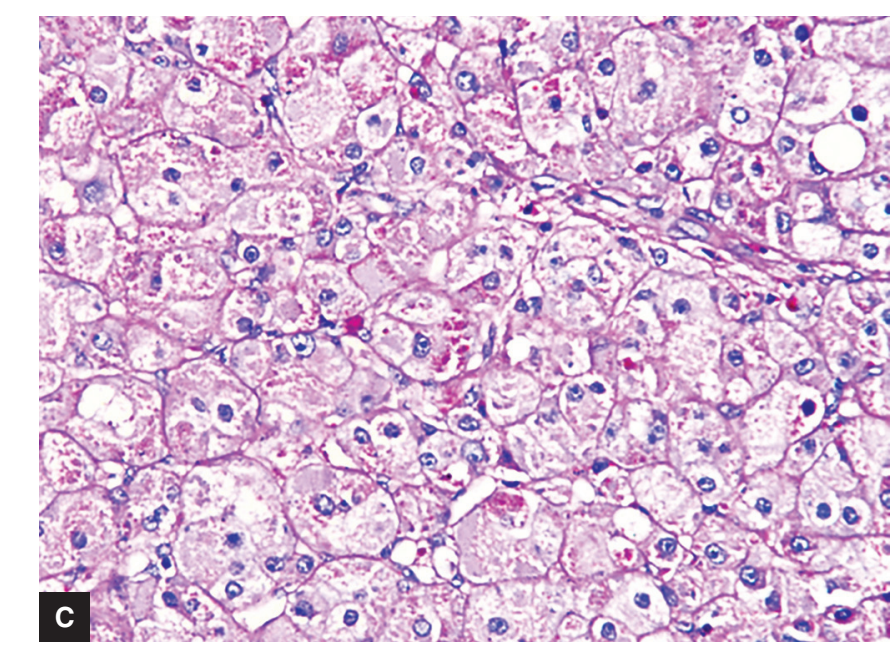

Figs 4A to C: (A) Masson Fontana; (B) Perl stain; and (C) Periodic acid Schiff stain

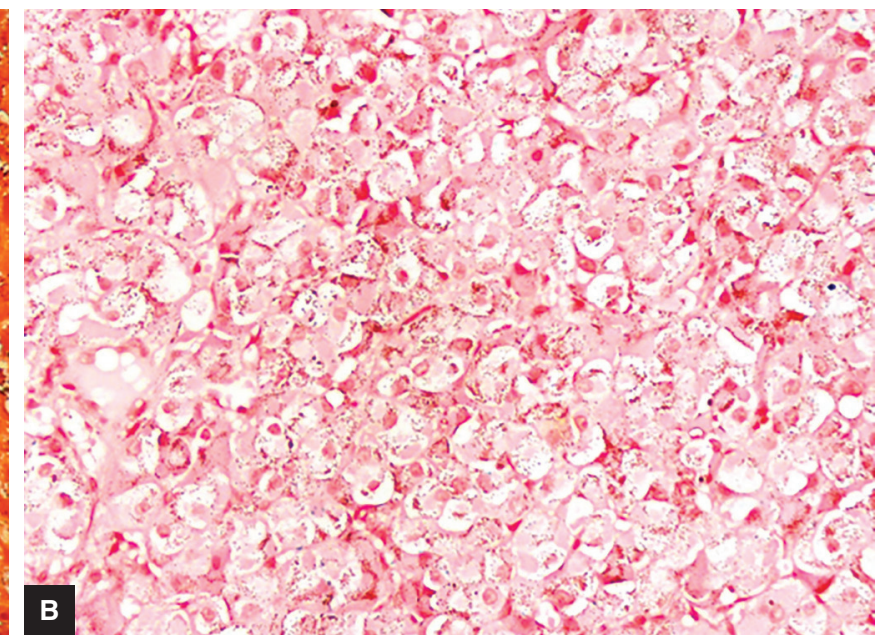


hyperaldosteronism, and a few even result in masculinization. ${ }^{7-9}$ Less frequently reported are nonfunctional black adrenal adenomas which present as incidentalomas. ${ }^{10}$ With the introduction of computed tomography (CT), magnetic resonance imaging (MRI), and fluorodeoxyglucose-positron emission tomography (FDG-PET), the imaging characteristics of adrenal adenomas in general and the distinct imaging features of black adrenal adenomas, in particular, have now been well described. Unlike most other adrenal adenomas, the black ones exhibit high Hounsfield units (>30) on CT, $85 \mathrm{HU}$ as observed in this case, a high T2 signal and lack of drop of the signal on out-of-phase imaging on MRI, and high standard uptake value (higher than that of liver) on FDG-PET, which all indicate less tumor lipid content but higher tissue density and blood supply, features suspicious of pheochromocytoma, interstitial tumors, and malignancy. ${ }^{10,11}$ Biologically, however, the black adrenal adenomas are benign without histological evidence of aggressiveness or invasiveness, as our patient's tumor. Black adrenal adenomas may be considered as one subtype of adrenal adenomas with atypical imaging characteristics. The clinical significance of lipofuscin pigments in black adrenal adenomas remains unclear.

\section{References}

1. Lam K-Y, Wat M-S. Adrenal cortical black adenoma: report of two cases and review of the literature. J Urol Pathol 1996;4:183-190. DOI: 10.1002/(SICl)1096-9926(199610)54:4<183::AID-TERA2>3.0.CO;2-2.

2. Macadam RF. Black adenoma of the human adrenal cortex. Cancer 1971;27:116-119.
3. Damron TA, Schelper RL, et al. Cytochemical demonstration of neuromelanin in black pigmented adrenal nodules. Am J Clin Pathol 1987;87:334-341.

4. Sienkowski IK, Watkins RM, et al. Primary tumours aldosteronism due to a black adrenal adenoma. A light and electron microscopic study. J Clin Pathol 1984;37:143-149.

5. Komiya I, Takasu N, et al. Black (or brown) adrenal cortical adenoma. Its characteristic features on computed tomography and endocrine data. J Clin Endocrinol Metab 1985;61:711-717. DOI: 10.1210/jcem-614-711.

6. Yu R, Wei M, et al. Black adrenal adenoma causing Cushing's syndrome: 40 years ago and today. Endocrinologia y nutricion: organo de la Sociedad Espanola de Endocrinologia y Nutricion 2015;62(9):466-469. DOI: 10.1016/j.endonu.2015.05.002.

7. Ueda $\mathrm{Y}$, Tanaka $\mathrm{H}$, et al. A functioning black adenoma of the adrenal gland. Intern. Med. 1997;36(6):398-402.

8. Cohen RJ, Brits R, et al. Primary hyperaldosteronism due to a functional black (pigmented) adenoma of the adrenal cortex. Arch Pathol Lab Med 1991;115(8):813-815.

9. Tanaka S, Tanabe A, et al. Glucocorticoid-and Androgen-Secreting Black Adrenocortical Adenomas: Unique Cause of CorticotropinIndependent Cushing Syndrome. Endocr Pract 2011;17(3): e73-e78.

10. Prince EA, Yoo DC, et al. CT and PET appearance of a pigmented "black" adrenal adenoma in a patient with lung cancer. Clin Radiol 2007;62(12):1229-1231. DOI: 10.1016/j.crad.2007.04.022.

11. Nakajo $M$, Nakajo $M$, et al. A black adrenal adenoma difficult to be differentiated from a malignant adrenal tumor by $\mathrm{CT}, \mathrm{MRI}$, scintigraphy and FDG PET/CT examinations. Ann Nucl Med 2011;25(10):812-817. DOI: 10.1007/s12149-011-0535-6. 